Virginia Commonwealth University

vCU Scholars Compass

\title{
Annealing temperature and initial iron valence ratio effects on the structural characteristics of nanoscale nickel zinc ferrite
}

\section{S. Calvin}

Sarah Lawrence College

\section{M.D. Schultz}

Virginia Commonwealth University

L. Glowzenski

Sarah Lawrence College

E. E. Carpenter

Virginia Commonwealth University, ecarpenter2@vcu.edu

Follow this and additional works at: http://scholarscompass.vcu.edu/chem_pubs

Part of the Chemistry Commons

Calvin, S., Schultz, M. D., \& Glowzenski, L., et al. Annealing temperature and initial iron valence ratio effects on the structural characteristics of nanoscale nickel zinc ferrite. Journal of Applied Physics, 107, 024301 (2010). Copyright (C) 2010 American Institute of Physics.

\section{Downloaded from}

http://scholarscompass.vcu.edu/chem_pubs/26

This Article is brought to you for free and open access by the Dept. of Chemistry at VCU Scholars Compass. It has been accepted for inclusion in Chemistry Publications by an authorized administrator of VCU Scholars Compass. For more information, please contact libcompass@vcu.edu. 


\title{
Annealing temperature and initial iron valence ratio effects on the structural characteristics of nanoscale nickel zinc ferrite
}

\author{
S. Calvin, ${ }^{1, a)}$ M. D. Shultz, ${ }^{2}$ L. Glowzenski, ${ }^{1}$ and E. E. Carpenter ${ }^{2}$ \\ ${ }_{1}^{1}$ Department of Physics, Sarah Lawrence College, 1 Mead Way, Bronxville, New York 10708, USA \\ ${ }^{2}$ Department of Chemistry, Virginia Commonwealth University, 1001 W. Main Street, Richmond, Virginia \\ 23284, USA
}

(Received 19 June 2009; accepted 6 November 2009; published online 19 January 2010)

\begin{abstract}
Nickel zinc ferrite (NZFO) nanoparticles were synthesized via a reverse micelle method with a nonionic surfactant. Three different initial $\mathrm{Fe}^{3+} / \mathrm{Fe}^{2+}$ ratios were employed along with three different firing temperatures $\left(200,500,1000{ }^{\circ} \mathrm{C}\right)$ to investigate the effects on the NZFO system. Extended x-ray absorption fine structure (EXAFS) results reveal zinc loss at high annealing temperatures; at $1000{ }^{\circ} \mathrm{C}$, the loss is nearly total for $\mathrm{Fe}^{3+} / \mathrm{Fe}^{2+}$ ratios other than $10: 90$. Annealing at $500{ }^{\circ} \mathrm{C}$, however, appears necessary for fully incorporating the zinc and nickel into the spinel phase. The best nanoferrite was thus obtained using an initial $\mathrm{Fe}^{3+} / \mathrm{Fe}^{2+}$ ratio of 10:90 and a moderate firing temperature of $500{ }^{\circ} \mathrm{C}$. This sample exhibits a room temperature saturation magnetization of $58 \mathrm{emu} / \mathrm{g}$ as measured via vibrating sample magnetometry, comparable with bulk values and greater than that of confirmed nano-NZFOs found in the literature. EXAFS also indicates that in all cases in which the elements adopted a spinel structure, the nickel occupies only octahedral sites and the zinc primarily tetrahedral sites. (C) 2010 American Institute of Physics. [doi:10.1063/1.3269706]
\end{abstract}

\section{INTRODUCTION}

Spinel ferrites, including nickel zinc ferrite (NZFO), have long been used in electromagnetic applications that require a high permeability, such as inductors and electromagnetic wave absorbers. In order to reduce energy losses associated with bulk powders, there have been many successful attempts to synthesize materials of this class as nanoparticles. ${ }^{1}$ The specific results for NZFO, however, have been somewhat inconsistent. Although some authors have reported syntheses free from complications, ${ }^{2}$ there have also been reports of undesirable site occupancies, ${ }^{3-7}$ nickel and zinc loss, ${ }^{3}$ partial segregation into nickel ferrite and zinc ferrite phases, ${ }^{3,8,9}$ the generation of nonspinel phases, ${ }^{6,10,11}$ and the formation of nickel metal during the annealing step. ${ }^{6}$

In the case of the related compound manganese zinc ferrite (MZFO), a previous study found that the hydroxide precipitation route has a pronounced effect on the cation occupancy and chemical composition of the ferrite, in turn affecting the magnetic and electronic properties. ${ }^{12}$ In the current paper, we use extended x-ray absorption fine structure (EXAFS) spectroscopy, supported by other methods of characterization, to examine whether the precipitation route has a similar effect on the synthesis of NZFOs. Our findings provide a possible explanation for some of the variability in previously published results.

\section{SYNTHESIS}

The synthesis of NZFO nanoparticles was performed, using Schlenk line techniques, by a synthetic route similar to the previously reported MZFO study. ${ }^{12}$ To form the micelles,

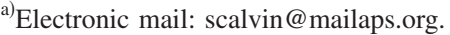

nonylphenoxy poly(ethyleneoxy-)ethanols were used; the species with 7 repeating units in the head group (NP7) as surfactant and the species with 4 repeating units in the head group (NP4) as cosurfactant. The volume fraction of $\mathrm{NP} 4$ / (NP4+NP7) was chosen at 0.25 , and this mixture was added to $102.5 \mathrm{ml}$ of cyclohexane so as to create a $0.37 \mathrm{M}$ solution. This solution was placed in an addition funnel, and an identical solution added to the reaction vessel below. In order to prevent the oxidation of the $\mathrm{Fe}(\mathrm{II})$ and ensure the proper initial $\mathrm{Fe}(\mathrm{III}) / \mathrm{Fe}$ (II) ratio, both solutions were thoroughly degassed under nitrogen before the next step. Chloride salts of $\mathrm{Ni}(\mathrm{II}), \mathrm{Zn}(\mathrm{II})$, and $\mathrm{Fe}(\mathrm{II} \&$ III) were then combined and dissolved in water at a respective mole ratio of 0.5:0.5:2.0, so as to produce a total iron concentration of $0.325 \mathrm{M}$ in $5.0 \mathrm{ml}$ of solution. According to the literature, these ratios should produce reverse micelles with a hydrodynamic diameter of approximately $8.34 \mathrm{~nm} .{ }^{13}$ The mixed metal chloride salt solution was then quickly added to the deoxygenated surfactant solution in the addition funnel and held under flowing nitrogen. Next, $5.0 \mathrm{ml}$ of concentrated ammonium hydroxide was added to the degassing surfactant solution in the reaction flask. Both reverse micelle systems were allowed to degas for no longer than 5 additional minutes prior to combining them in the reaction flask, in order to limit both the $\mathrm{Fe}(\mathrm{II})$ oxidation to $\mathrm{Fe}(\mathrm{III})$ and ammonia loss from degassing. Next, the two reverse micelle solutions were combined in the reaction flask while keeping the system under flowing nitrogen. Upon combination, the solution went through either a green to black or orange to black color change, depending on the precipitation route, ${ }^{12}$ which was varied by altering the initial $\mathrm{Fe}$ (III)/ $\mathrm{Fe}$ (II) ratio. Three ratios of $90: 10,50: 50$, and 10:90 were chosen so as to give the greatest difference in precipitation route for the annealing 
investigation. The reaction was aged for $30 \mathrm{~min}$ and then subsequently quenched by the addition of degassed 50/50 methanol/acetone solution through the addition funnel. The resultant particles were washed with methanol two more times by collection via centrifugation, dried under vacuum, and divided into three equal amounts.

The samples were then fired for $5 \mathrm{~h}$ under nitrogen at three different temperatures $\left(200,500\right.$, and $\left.1000{ }^{\circ} \mathrm{C}\right)$, yielding nine total variations. The temperatures were chosen because $200{ }^{\circ} \mathrm{C}$ is the lowest temperature at which the surfactant could be eliminated from the particles, $500{ }^{\circ} \mathrm{C}$ is a known moderate firing temperature for ferrite synthesis, and $1000{ }^{\circ} \mathrm{C}$ is a high firing temperature that would be expected to give enough energy for zinc to migrate to the surface and sublime away. In the remainder of this paper, samples will be identified by (firing temperature, initial $\mathrm{Fe}(\mathrm{III}) \%$ ). For example, a sample that was fired at $500{ }^{\circ} \mathrm{C}$ and synthesized with an initial $\mathrm{Fe}(\mathrm{III}) / \mathrm{Fe}(\mathrm{II})$ ratio of $10: 90$ will be denoted as $\left(500{ }^{\circ} \mathrm{C}, 10 \%\right)$.

\section{CHARACTERIZATION}

\section{A. X-ray absorption spectroscopy}

$\mathrm{X}$-ray absorption spectra of the iron, nickel, and zinc $\mathrm{K}$ edges were collected at beamline X-11B of the National Synchrotron Light Source at Brookhaven National Laboratory and analyzed by fitting the spectra to ab initio theoretical standards. ${ }^{14}$ Background subtraction was performed using the method of Newville et al., ${ }^{15}$ followed by a normalization correction based on the data of McMaster. ${ }^{16}$ After background subtraction, data were transformed to a function of photoelectron wavenumber $k$. Since EXAFS amplitude generally falls off with increasing $k$, the data were multiplied by $k^{3}$ prior to taking the Fourier transform (Fig. 1). Due to zinc loss with heating, the zinc spectra for the $\left(1000{ }^{\circ} \mathrm{C}, 50 \%\right)$ and $\left(1000{ }^{\circ} \mathrm{C}, 90 \%\right)$ samples were nearly absent, and thus do not appear in the figures.

The chemical composition of each sample was determined by comparing the size of the jump in each element's absorption edge to the normalized atomic absorption tabulated in Ref. 17. The results are given in Table I. Note that substantial zinc loss occurs with all samples for annealing at $1000{ }^{\circ} \mathrm{C}$.

For all samples, data were selected over a range of 2.5-10.0 $\AA^{-1}$ for the iron edge, 2.5-9.0 $\AA^{-1}$ for the zinc edge, and 2.5-6.7 $\AA^{-1}$ for the nickel edge. (The nickel edge spectra showed a substantial monochromator glitch just above $7 \AA^{-1}$, necessitating the cutoff at $6.7 \AA^{-1}$.) The data were then Fourier transformed using Hanning windows with sills of size $1.0 \AA^{-1}$. The magnitudes of the Fourier transforms, along with a standard for comparison, are shown in Fig. 2. (The spectra shown for the ceramic NZFO standard were collected on beamline X-11A at an earlier time. ${ }^{3}$ As a precaution against beamline-dependent effects, one scan on each edge of the standard was retaken at X-11B; the resulting spectra showed negligible differences from the original $\mathrm{X}-11 \mathrm{~A}$ data.)

Inspection of Fig. 2 shows several clear trends. At $200{ }^{\circ} \mathrm{C}$ annealing temperature, the zinc cations have not yet
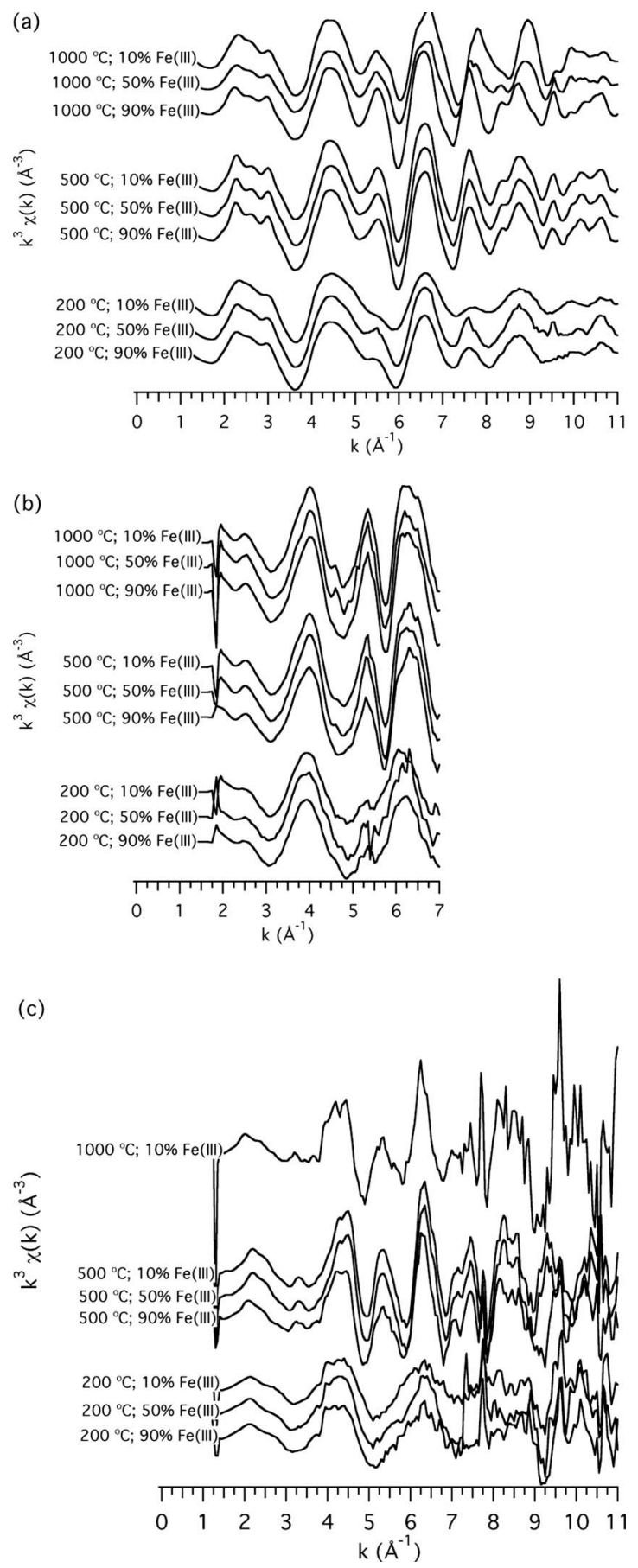

FIG. 1. $\chi(k)$ data for all samples. (a) Iron edge; (b) nickel edge; and (c) zinc edge.

entered sites in the spinel lattice. At that same temperature, the nickel and iron cations do show indications of adopting a spinel structure, albeit with substantial disorder beyond the nearest neighbor. Considering the loss of zinc exhibited at $1000{ }^{\circ} \mathrm{C}, 500{ }^{\circ} \mathrm{C}$ is therefore the best annealing temperature of the three tested. At that temperature, choosing $10 \%$ of the starting iron to be in the +3 oxidation state yields the zinc spectrum showing the greatest degree of order and the greatest similarity to the standard. This also correlates to the behavior at $1000{ }^{\circ} \mathrm{C}$, where only the sample with $10 \%$ starting $\mathrm{Fe}(\mathrm{III})$ maintains enough zinc to exhibit a measurable spectrum. This observation corroborates the mechanism behind 
TABLE I. Parameters for all samples.

\begin{tabular}{|c|c|c|c|c|c|c|c|c|c|c|}
\hline $\begin{array}{l}\text { Anneal temperature } \\
\left({ }^{\circ} \mathrm{C}\right)\end{array}$ & Standard & 200 & 200 & 200 & 500 & 500 & 500 & 1000 & 1000 & 1000 \\
\hline $\begin{array}{l}\mathrm{Fe}(\mathrm{III}) \\
(\%)\end{array}$ & Standard & 90 & 50 & 10 & 90 & 50 & 10 & 90 & 50 & 10 \\
\hline \multicolumn{11}{|l|}{ Chemical composition: } \\
\hline Iron & $64(9)$ & $84(6)$ & $83(6)$ & $84(6)$ & $85(5)$ & $84(5)$ & $87(5)$ & $90(4)$ & $90(4)$ & $89(4)$ \\
\hline Nickel & $18(6)$ & $10(4)$ & $9(4)$ & $7(4)$ & $9(4)$ & $8(4)$ & $7(4)$ & $10(4)$ & $9(4)$ & $9(4)$ \\
\hline Zinc & $18(6)$ & $7(3)$ & $8(4)$ & $9(4)$ & $6(2)$ & $7(4)$ & $6(3)$ & $<1$ & $2(1)$ & $2(2)$ \\
\hline \multicolumn{11}{|l|}{$\mathcal{R}$-factor: } \\
\hline Iron & 0.021 & 0.051 & 0.048 & 0.051 & 0.024 & 0.024 & 0.022 & 0.066 & 0.066 & 0.148 \\
\hline Nickel & 0.043 & 0.022 & 0.014 & 0.047 & 0.029 & 0.039 & 0.037 & 0.120 & 0.120 & 0.132 \\
\hline Zinc & 0.031 & 0.338 & 0.267 & 0.212 & 0.045 & 0.038 & 0.020 & 0.180 & 0.488 & 0.200 \\
\hline \multicolumn{11}{|l|}{$S_{o}^{2}$} \\
\hline Iron & $2.09(20)$ & $1.83(21)$ & 1.73(19) & $1.97(22)$ & $1.88(16)$ & $1.85(16)$ & 1.91(16) & $1.55(28)$ & $1.55(25)$ & $1.31(31)$ \\
\hline Nickel & $1.08(12)$ & $0.99(37)$ & $0.92(33)$ & $1.10(54)$ & $1.32(24)$ & $1.53(27)$ & $1.42(28)$ & $1.52(49)$ & $1.52(43)$ & $1.05(48)$ \\
\hline Zinc & $0.58(11)$ & $0.29(43)$ & $0.35(28)$ & $0.34(42)$ & $0.52(33)$ & $0.56(24)$ & $0.63(30)$ & $0.87(156)$ & $0.45(91)$ & $0.56(45)$ \\
\hline \multicolumn{11}{|l|}{$E_{o}(\mathrm{eV}):$} \\
\hline Iron & $7117(1)$ & $7113(1)$ & $7114(1)$ & $7114(1)$ & $7115(1)$ & $7115(4)$ & $7115(1)$ & $7112(2)$ & $7112(2)$ & $7108(2)$ \\
\hline Nickel & $8336(2)$ & $8332(3)$ & $8332(3)$ & $8332(4)$ & $8333(2)$ & $8334(2)$ & $8334(2)$ & $8330(3)$ & $8330(2)$ & $8326(4)$ \\
\hline Zinc & $9668(5)$ & $9665(10)$ & $9668(5)$ & $9665(8)$ & $9660(5)$ & $9660(3)$ & $9661(4)$ & $\cdots$ & $9649(37)$ & $9651(41)$ \\
\hline Lattice parameter $(\AA)$ & $8.43(2)$ & $8.39(4)$ & $8.40(3)$ & $8.42(5)$ & $8.38(3)$ & $8.39(3)$ & $8.39(2)$ & $8.25(4)$ & $8.25(4)$ & $8.11(5)$ \\
\hline Oxygen parameter & $0.394(4)$ & $0.404(9)$ & $0.402(8)$ & $0.404(10)$ & $0.398(5)$ & $0.398(4)$ & $0.397(4)$ & $0.397(10)$ & $0.397(8)$ & $0.394(13)$ \\
\hline \multicolumn{11}{|c|}{ First shell distortion (\%): } \\
\hline Iron & $-0.005(3)$ & $-0.015(5)$ & $-0.018(4)$ & $-0.015(6)$ & $-0.011(3)$ & $-0.011(3)$ & $-0.010(3)$ & $-0.002(5)$ & $-0.002(5)$ & $0.001(6)$ \\
\hline Nickel & $0.034(7)$ & $0.024(15)$ & $0.022(15)$ & $0.024(21)$ & $0.025(11)$ & $0.031(12)$ & $0.028(13)$ & $0.028(21)$ & $0.028(18)$ & $0.023(25)$ \\
\hline Zinc & $-0.01(2)$ & $-0.01(6)$ & $0.02(4)$ & $-0.01(4)$ & $-0.01(4)$ & $-0.02(3)$ & $-0.02(4)$ & $0.02(6)$ & $-0.06(6)$ & $0.00(20)$ \\
\hline Outer MSRD $\left(\AA^{2}\right)$ & $0.009(1)$ & $0.018(2)$ & $0.015(2)$ & $0.026(2)$ & $0.010(1)$ & $0.010(1)$ & $0.010(1)$ & $0.012(2)$ & $0.012(2)$ & $0.007(2)$ \\
\hline \multicolumn{11}{|l|}{ First-shell MSRD $\left(\AA^{2}\right)$ : } \\
\hline Iron & $0.011(1)$ & $0.010(2)$ & $0.010(2)$ & $0.011(3)$ & $0.010(1)$ & $0.010(1)$ & $0.011(1)$ & $0.012(3)$ & $0.012(2)$ & $0.007(5)$ \\
\hline Nickel & $0.010(3)$ & $0.006(7)$ & $0.002(6)$ & $0.008(9)$ & $0.013(4)$ & $0.014(5)$ & $0.015(6)$ & $0.017(9)$ & $0.017(7)$ & $0.007(8)$ \\
\hline Zinc & $0.008(5)$ & $0.002(21)$ & $0.001(12)$ & $0.003(17)$ & $0.006(14)$ & $0.007(11)$ & $0.007(13)$ & $-0.007(15)$ & $-0.008(7)$ & $-0.005(68)$ \\
\hline
\end{tabular}

higher levels of zinc incorporation proposed in the aforementioned MZFO study. ${ }^{12}$ With the initial iron valence state predominantly +2 , the precipitation route should begin as chlorine containing green rust, thereby aiding the inclusion of $\mathrm{Zn}$ (II) in the core of the nanoparticles as they formed. This would lead to the retention of $\mathrm{Zn}$ (II) to higher temperatures, as was observed.

Previous studies ${ }^{18,19}$ have established that, for spinel ferrites, the peak in the Fourier transform near $2.7 \AA$ is primarily due to absorbers in octahedrally coordinated sites, while the peak near $3.2 \AA$ is primarily due to absorbers in tetrahedrally coordinated sites. With that in mind, Fig. 2 shows that zinc is nearly entirely in tetrahedral sites, particularly for the highly ordered $\left(500{ }^{\circ} \mathrm{C}, 10 \%\right)$ sample. This peak shows a modest trend toward lower values of $R_{\text {eff }}$ as the proportion of starting Fe(III) is increased. While this may indicate a small proportion of zinc residing in octahedral sites, this cannot be confirmed without the resolution of a corresponding shoulder at $2.7 \AA$. As no shoulder is visible, the peak shift is more likely attributable to some other effect, such as the presence of a small amount of zinc in a nonspinel phase.

Using the same heuristic, the nickel Fourier transform shows entirely octahedral occupancy for all samples. The corresponding iron peak shows the most complicated behavior. For all samples at $500{ }^{\circ} \mathrm{C}$, the iron shows a peak around $2.8 \AA$ with a shoulder on the high- $R_{\text {eff }}$ side, as would be expected if the majority of iron is in octahedral sites but with a substantial minority in tetrahedral sites, consistent with the chemical compositions of the samples and the occupancies determined for the other two elements.

Quantitative fitting was then performed, using the model described in Ref. 20, over a range of 1.0-4.5 $\AA$ on the iron and nickel edges and 1.2-4.5 $\AA$ on the zinc edges. (For each sample, this yields 39 independent points according to the Nyquist criterion.) This model comprises a simultaneous corefinement of the three cation edges, with the site occupancy of iron constrained by the occupancies of the other 

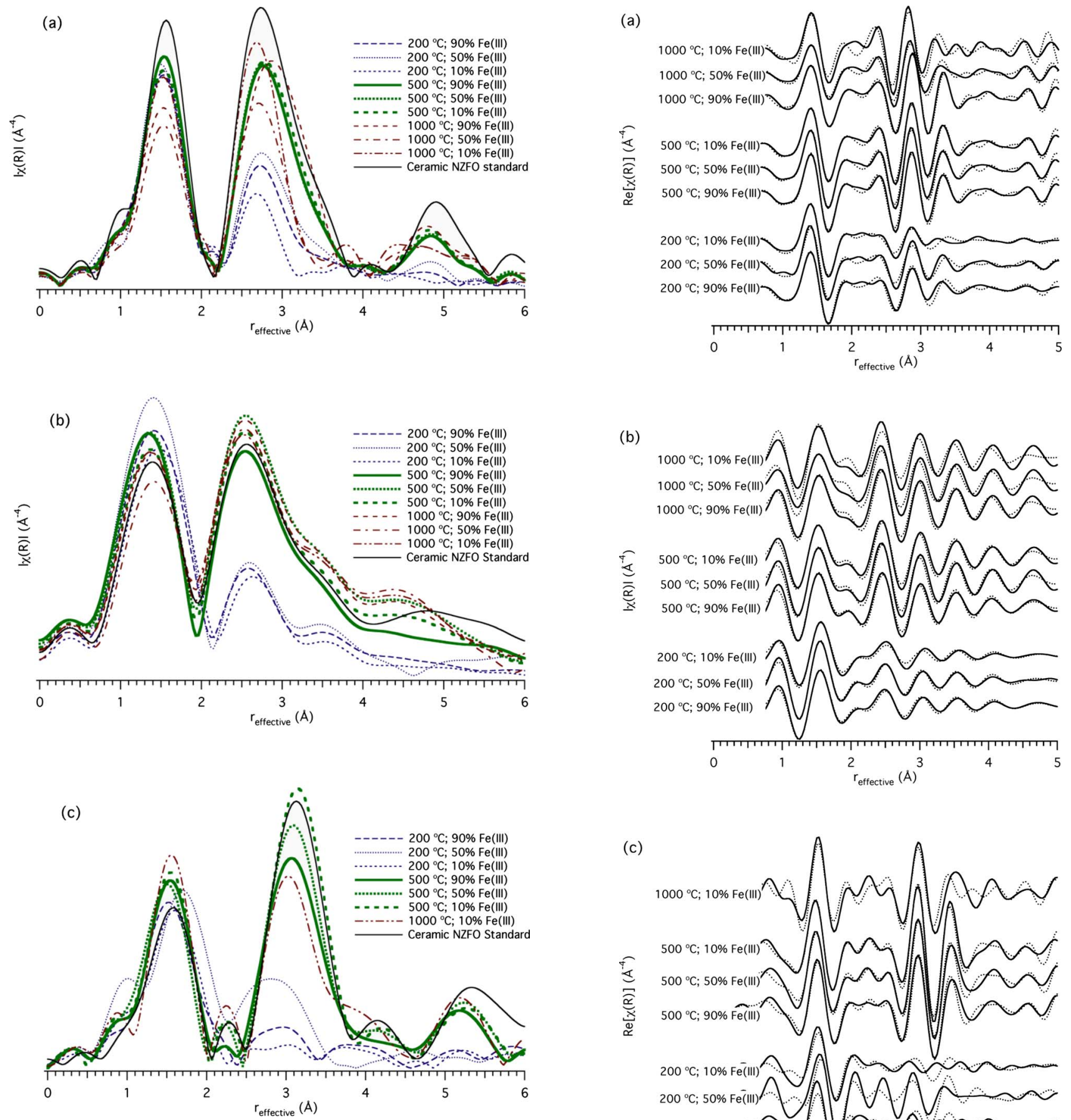

FIG. 2. (Color online) The magnitude of the Fourier transform of the data for each sample and the standard. (a) Iron edge; (b) nickel edge; and (c) zinc edge.

two elements and the chemical composition of the sample. As a precaution, the site occupancies for nickel and zinc were initially allowed to vary as in Ref. 20 , but it was found that all fits on all samples refined to zinc ions solely in tetrahedral sites and nickel ions solely in octahedral sites, in agreement with the qualitative analysis in the preceding paragraphs. In the fits presented here, therefore, 15 parameters were allowed to vary: an EXAFS amplitude reduction factor for each edge ( $S_{o}^{2} ; 3$ parameters); the photoelectron energy origin for each edge $\left(E_{o} ; 3\right.$ parameters); the lattice parameter; the spinel oxygen parameter; ${ }^{21}$ a local distortion

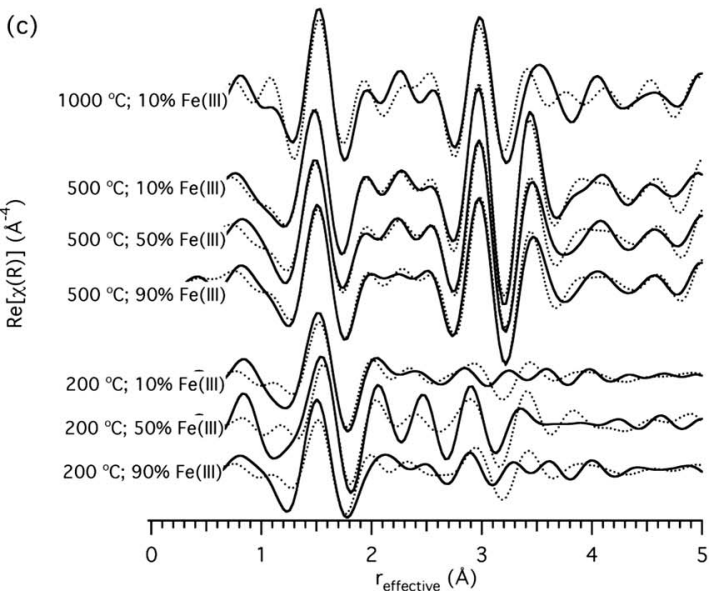

FIG. 3. Real part of Fourier transform of all samples with corresponding fits. (a) Iron edge; (b) nickel edge; and (c) zinc edge.

in the nearest-neighbor cation-oxygen distance for each element (3 parameters); a mean-square radial displacement for cation-oxygen nearest-neighbors for each element (MSRD; 3 parameters); and a mean-square radial displacement for all more distant pairs. In the fits, each element's edge was given a weighting proportional to the size of its edge jump (i.e., the absorption attributable to that edge). The results of these fits are shown in Fig. 3 and Table I. Table I also includes the "EXAFS $\mathcal{R}$-factor," which is given by 


$$
\mathcal{R}=\frac{\sum_{i}\left[\widetilde{\chi}_{\mathrm{fit}}\left(r_{i} ; \text { varied parameters }\right)-\widetilde{\chi}_{\text {data }}\left(r_{i}\right)\right]^{2}}{\sum_{i}\left[\widetilde{\chi}_{\text {data }}\left(r_{i}\right)\right]^{2}},
$$

where $\tilde{\chi}$ represents the complex Fourier transform of the EXAFS and the $r_{i}$ 's are equally spaced points in the complex Fourier transform. Although the EXAFS $\mathcal{R}$-factor cannot be used to evaluate statistical significance, it is widely used in the field to describe closeness of fit. Previous work with MZFO (Ref. 20) has established that applying this procedure to ceramic standards yields values of $\mathcal{R}$ below 0.05 ; applying this model to a ceramic NZFO standard confirms that this threshold holds in this case as well.

The $\mathcal{R}$-factors given in Table I confirm that, at $200{ }^{\circ} \mathrm{C}$, the zinc was not yet incorporated into the spinel lattice. At $1000{ }^{\circ} \mathrm{C}$, the $\mathcal{R}$-factor for all edges exceeds 0.05 , suggesting that it is no longer appropriate to say that the material consists solely of a single-phase spinel lattice. While all three samples at $500{ }^{\circ} \mathrm{C}$ exhibit $\mathcal{R}$-factors consistent with a single-phase spinel, the quality of the zinc fit does show a correlation with the initial oxidation state of the iron, with a low fraction of $\mathrm{Fe}$ (III) yielding the best fit. (The other two edges do not exhibit a clear trend in $\mathcal{R}$-factor).

The other fitted parameters are generally consistent with the NZFO structure. The EXAFS amplitude reduction factors are somewhat outside of the expected range for EXAFS of $0.70-1.0$, yielding values that are somewhat high for the iron, and to a lesser extent, the nickel edges, and somewhat low for the zinc edge. We have been unable to ascertain the cause of this anomaly, but it is also present in the fit of the standard. This suggests that it is a systematic effect of applying the model of Ref. 20 to NZFO, and is not indicative of a structural peculiarity in the samples relative to the standard. One possible explanation is that the model only allows for four mean-square radial displacement parameters. Correlations between fitted parameters make it difficult to allow for more in these fits, but by suppressing the degrees of freedom associated with thermal and static disorder the model may introduce distortions into the correlated amplitude reduction parameters.

\section{B. Transmission electron microscopy and powder $\mathrm{x}$ - ray diffraction}

Transmission electron microscopy (TEM) and powder $\mathrm{x}$-ray diffraction (XRD) were performed on select samples in order to confirm the nanomorphology and spinel structure of the synthesized particles. Figure 4 shows the TEM of the $\left(500{ }^{\circ} \mathrm{C}, 10 \%\right)$ NZFO particles, along with an inset showing XRD patterns for the $\left(500{ }^{\circ} \mathrm{C}, 10 \%\right),\left(200{ }^{\circ} \mathrm{C}, 50 \%\right)$, and $\left(200{ }^{\circ} \mathrm{C}, 90 \%\right)$ samples. As seen in the TEM image, the $\left(500{ }^{\circ} \mathrm{C}, 10 \%\right)$ NZFO particles are roughly spherical with an average diameter of $16.3 \pm 2.7 \mathrm{~nm}$. This was generally representative of all samples. The inset XRD pattern for $\left(500{ }^{\circ} \mathrm{C}, 10 \%\right)$ confirms the spinel structure; application of the Scherrer equation to these peaks yielded an average crystallite size of $19.5 \pm 5.2 \mathrm{~nm}$, which is in good agreement with the size measured on TEM and suggests a fairly monodisperse sample. ${ }^{22}$ The XRD pattern for the $\left(200{ }^{\circ} \mathrm{C}, 50 \%\right)$

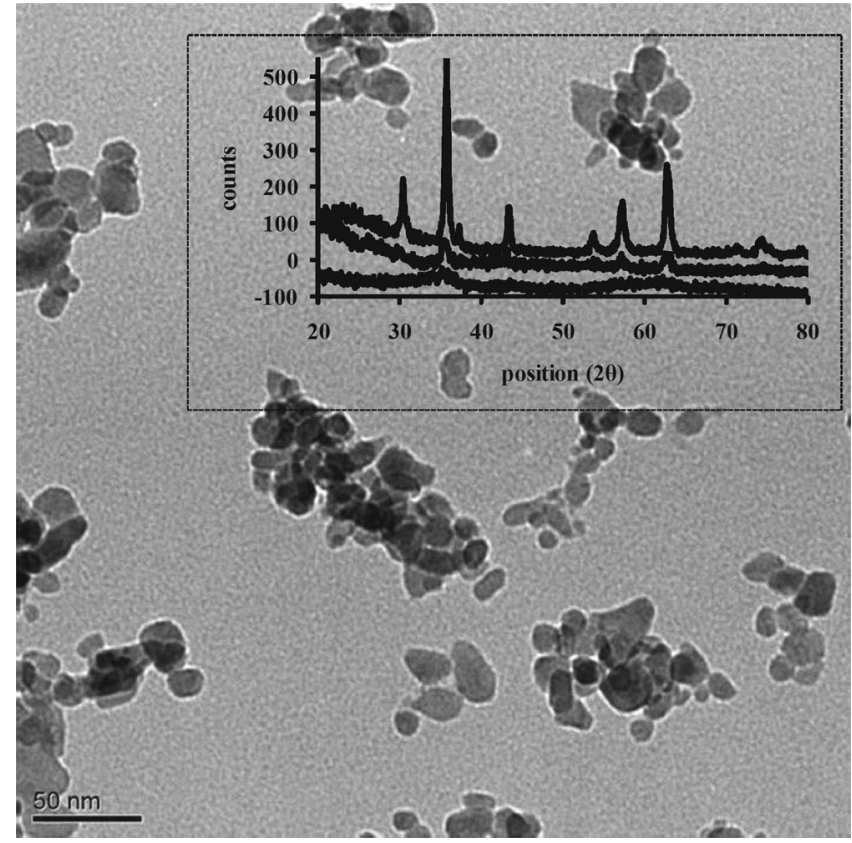

FIG. 4. TEM image of NZFO nanoparticles synthesized with initial Fe(III) percentage of $10 \%$, annealed at $500{ }^{\circ} \mathrm{C}$. Inset: diffraction pattern for NZFO nanoparticles synthesized with initial $\mathrm{Fe}(\mathrm{III})$ percentage of $10 \%$ annealed at $500{ }^{\circ} \mathrm{C}$ (top trace); with initial $\mathrm{Fe}$ (III) percentage of $50 \%$ annealed at $200{ }^{\circ} \mathrm{C}$ (middle trace); and with initial Fe(III) percentage of $90 \%$ annealed at $200{ }^{\circ} \mathrm{C}$ (bottom trace).

shows peaks at corresponding angles, but with much less crystallinity. The $\left(200{ }^{\circ} \mathrm{C}, 90 \%\right)$ pattern shows only very broad peaks, although the locations again appear to correspond to the strongest reflections of a spinel pattern. The degradation of crystallinity in this series of XRD patterns corresponds to the increase in $\mathcal{R}$-factors seen in the EXAFS modeling, supporting those results.

\section{Vibrating sample magnetometry}

To confirm the interpretation of the initial iron valence ratio effect at the preferred annealing temperature of $500{ }^{\circ} \mathrm{C}$, magnetic characterization via vibrating sample magnetometry was carried out on the $\left(500{ }^{\circ} \mathrm{C}, 10 \%\right)$ and $\left(500{ }^{\circ} \mathrm{C}\right.$, 90\%) samples. As can be seen in Fig. 5, the saturation magnetization measured at room temperature for the $90 \% \mathrm{Fe}$ (III) sample is about $31 \mathrm{emu} / \mathrm{g}$ (comparable to literature values), while the saturation magnetization for the $10 \% \mathrm{Fe}$ (III) sample is around $58 \mathrm{emu} / \mathrm{g}$, which is better than most literature values under similar firing conditions. ${ }^{3,7,23,24}$ (Some literature reports greater saturation values at higher annealing temperatures, but fail to report pre- and/or postannealing elemental analysis for the metals' stoichiometric determination. ${ }^{23,24}$ Since we show drastic zinc loss at higher temperatures, and since crystallite growth can also be expected at high temperatures, it is not clear that in those cases that it is really nanocrystalline NZFO that is being characterized.) Our magnetization results support the evidence from EXAFS that the zinc is more effectively incorporated into the spinel lattice when the initial source of iron cations is primarily in the +2 state. 


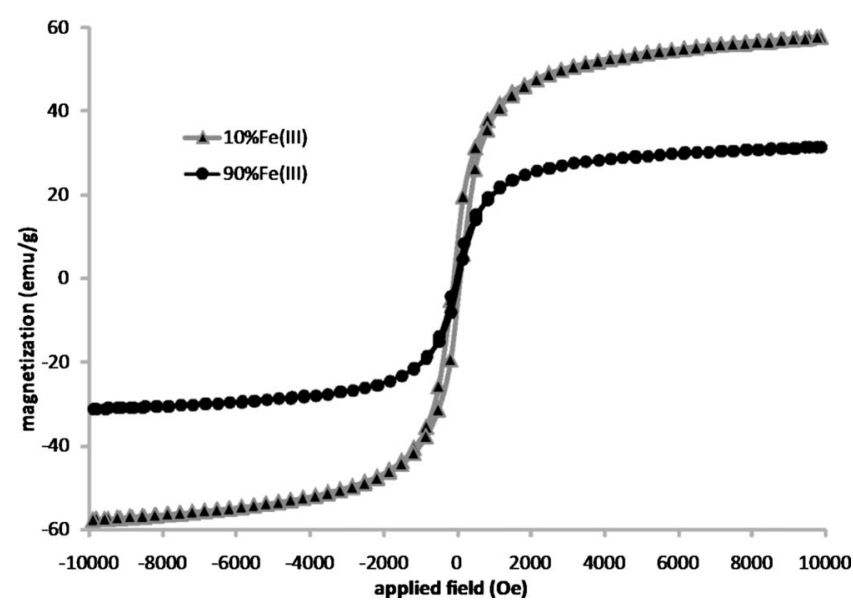

FIG. 5. Hysteresis plot measured at room temperature for NZFO nanoparticles synthesized with initial Fe(III) percentages of $10 \%$ and $90 \%$, annealed at $500{ }^{\circ} \mathrm{C}$.

\section{CONCLUSION}

In conclusion, annealing at $200{ }^{\circ} \mathrm{C}$ does not allow zinc to be incorporated into the spinel structure, and annealing at $1000{ }^{\circ} \mathrm{C}$ causes total zinc loss and a breakdown of the single-phase spinel, while $500{ }^{\circ} \mathrm{C}$ yields nearly pure-phase NZFO nanoparticles. In addition, zinc appears to be incorporated most effectively when the initial source of iron cations are primarily in the +2 oxidation state, demonstrating that this may be an important variable to consider for successful syntheses of this material.

${ }^{1}$ D. S. Mathew and R.-S. Juang, Chem. Eng. J. 129, 51 (2007).

${ }^{2}$ V. Uskoković, M. Drofenik, and I. Ban, J. Magn. Magn. Mater. 284, 294 (2004).

${ }^{3}$ S. A. Morrison, C. L. Cahill, E. E. Carpenter, S. Calvin, R. Swaminathan, M. E. McHenry, and V. G. Harris, J. Appl. Phys. 95, 6392 (2004).

${ }^{4}$ N. Ponpandian, A. Narayanasamy, C. N. Chinnasamy, N. Sivakumar, J.-M. Greneche, K. Chattopadhyay, K. Shinoda, B. Jeyadevan, and K.
Tohji, Appl. Phys. Lett. 86, 192510 (2005).

${ }^{5}$ Z. Beji, T. Ben Chaabane, L. S. Smiri, S. Ammar, F. Fiévet, N. Jouini, and J. M. Grenèche, Phys. Status Solidi A 203, 504 (2006).

${ }^{6}$ R. Swaminathan, J. Woods, S. Calvin, J. Huth, and M. E. McHenry, Adv. Sci. Technol. 45, 2337 (2006).

${ }^{7}$ B. T. Naughton, P. Majewski, and D. R. Clarke, J. Am. Chem. Soc. 90, 3541 (2007).

${ }^{8}$ C. Caizer and M. Stefanescu, J. Phys. D: Appl. Phys. 35, 3035 (2002).

${ }^{9}$ R. Swaminathan, M. E. McHenry, S. Calvin, M. Sorescu, and L. Diamandescu, in Proceedings of the Ninth International Conference on Ferrites, San Francisco, CA, 2004, edited by R. F. Soohoo (Wiley, Hoboken, 2005), pp. 847-852.

${ }^{10}$ A. C. F. M. Costa, V. J. Silva, D. R. Cornejo, M. R. Morelli, R. H. G. A. Kiminami, and L. Gama, J. Magn. Magn. Mater. 320, e370 (2008).

${ }^{11}$ U. R. Lima, M. C. Nasar, R. S. Nasa, M. S. Rezende, and J. H. Araújo, J. Magn. Magn. Mater. 320, 1666 (2008).

${ }^{12}$ M. D. Shultz, M. J. Allsbrook, and E. E. Carpenter, J. Appl. Phys. 101, 09M518 (2007).

${ }^{13}$ M. A. Michaels, S. Sherwood, M. Kidwell, M. J. Allsbrook, S. A. Morrison, S. C. Rutan, and E. E. Carpenter, J. Colloid Interface Sci. 311, 70 (2007).

${ }^{14}$ J. J. Rehr and R. C. Albers, Rev. Mod. Phys. 72, 621 (2000).

${ }^{15}$ M. Newville, P. Līvinuš, Y. Yacoby, J. J. Rehr, and E. A. Stern, Phys. Rev. B 47, 14126 (1993).

${ }^{16}$ W. H. McMaster, N. K. del Grande, J. H. Mallett, and J. H. Hubbell, LLNL Report No. UCRL-50174, 1969.

${ }^{17}$ W. T. Elam, B. D. Ravel, and J. R. Sieber, Radiat. Phys. Chem. 63, 121 (2002).

${ }^{18}$ P. C. Doresy, V. G. Harris, D. B. Christy, P. Lubitz, J. S. Horowitz, and N. C. Koon, in Applications of Synchrotron Radiation Techniques to Materials Science, edited by D. L. Petty, N. Shinn, K. D. Amico, G. Ice, and L. Terminello (Materials Research Society, Pittsburgh, 1995), Vol. 375, p. 33.

${ }^{19}$ V. G. Harris, N. C. Koon, C. M. Williams, Q. Zhang, M. Abe, J. P. Kirkland, and D. A. McKeown, IEEE Trans. Magn. 31, 3473 (1995).

${ }^{20}$ S. Calvin, E. E. Carpenter, B. Ravel, V. G. Harris, and S. A. Morrison, Phys. Rev. B 66, 224405 (2002).

${ }^{21}$ J. Smit and H. P. J. Wijn, Ferrites (Wiley, New York, 1959), pp. 139-140.

${ }^{22}$ S. Calvin, C. J. Riedel, E. E. Carpenter, S. A. Morrison, R. M. Stroud, and V. G. Harris, Phys. Scr., T 115, 744 (2005).

${ }^{23}$ S. Singhal, A. N. Garg, and K. Chandra, Hyperfine Interact. 156/157, 97 (2004).

${ }^{24}$ A. M. Kumar, M. C. Varma, C. L. Dube, K. H. Rao, and S. C. Kashyap, J. Magn. Magn. Mater. 320, 1995 (2008). 